\title{
Long-term complete remission in a patient with intravascular large B-cell lymphoma with central nervous system involvement
}

This article was published in the following Dove Press journal:

OncoTargets and Therapy

I8 November 2014

Number of times this article has been viewed

\author{
Takeshi Sawada' \\ Yasushi Omuro' \\ Takeshi Kobayashi ${ }^{2}$ \\ Tunekazu Hishima ${ }^{3}$ \\ Fumiaki Koizumi ${ }^{4}$ \\ Yusuke Kanemasa' \\ Tatsu Shimoyama' \\ Eisaku Sasaki' \\ Yoshiharu Maeda' \\ 'Department of Chemotherapy, \\ ${ }^{2}$ Department of Hematology, \\ ${ }^{3}$ Department of Pathology, \\ ${ }^{4}$ Department of Laboratory Medicine, \\ Tokyo Metropolitan Cancer \\ and Infectious Diseases Center, \\ Komagome Hospital, Bunkyo-ku, \\ Tokyo, Japan
}

\begin{abstract}
This report describes a patient with intravascular large B-cell lymphoma (IVLBCL) with central nervous system involvement at the time of diagnosis who achieved complete remission for over 5 years in response to therapy. The patient, a 71 year-old woman, was previously healthy with the exception of taking verapamil for paroxysmal supraventricular tachycardia. She had presented with pyrexia and gradually progressive anemia. Brain magnetic resonance imaging revealed an infarct-like lesion in the pons, although no paralysis was observed. She was diagnosed with IVLBCL on the basis of random skin biopsy. After eight cycles of rituximab plus cyclophosphamide, doxorubicin, vincristine, and prednisone therapy, abnormal laboratory data had normalized, and no pontine lesion was evident on magnetic resonance imaging without receiving any intrathecal chemotherapy. IVLBCL is associated with poor prognosis, particularly in patients with central nervous system involvement. Early initiation of rituximab plus cyclophosphamide, doxorubicin, vincristine, and prednisone therapy and drug interactions between anticancer agents and verapamil as a p-glycoprotein inhibitor were considered the possible reasons for favorable outcome in the present case.
\end{abstract}

Keywords: intravascular large B-cell lymphoma, random skin biopsy, CNS involvement, rituximab, verapamil, blood-brain barrier

\section{Introduction}

Intravascular large B-cell lymphoma (IVLBCL) is a rare and aggressive variant of extranodal large B-cell lymphoma with frequent involvement of the central nervous system (CNS) characterized by proliferation of large lymphoma cells within the lumina of the small vessels. ${ }^{1}$ The lack of characteristic clinical symptoms and the absence of lymphadenopathy can make the diagnosis of IVLBCL quite difficult, and the prognosis for patients with this disease is extremely poor. ${ }^{2}$ The recent use of random skin biopsies has enabled earlier diagnosis of IVLBCL. ${ }^{3}$ While the anti-CD20 monoclonal antibody, rituximab, can improve survival for patients with IVLBCL, ${ }^{4}$ those with CNS involvement still have poor outcomes. ${ }^{5}$ The present report describes the first reported case of a patient with IVLBCL who was diagnosed in the early phase by a random skin biopsy and who was successfully treated with rituximab plus cyclophosphamide, doxorubicin, vincristine, and prednisone (R-CHOP) therapy without any intrathecal treatment.

\section{Case presentation}

A 71 year-old woman had intermittent pyrexia $\left(>38^{\circ} \mathrm{C}\right)$ for 1 week in May 2009. Her family doctor treated her with a course of antibiotics to no effect. 
Computed tomography (CT), cardiac ultrasonography, and tuberculosis skin test detected no abnormalities. General malaise gradually developed, and hemoglobin $(\mathrm{Hb})$ level fell from $10.2 \mathrm{~g} / \mathrm{dL}$ to $9.0 \mathrm{~g} / \mathrm{dL}$ over 2 weeks. She was admitted to our hospital as a case of fever of unknown origin. On admission, pyrexia was the only abnormality on vital signs. She was taking no medications other than verapamil and digoxin for paroxysmal supraventricular tachycardia. Meticulous physical examination detected anemic conjunctivae and edema of the bilateral lower extremities. No skin lesions, palpable lymph nodes, or neurological abnormalities were evident. Laboratory findings showed anemia ( $\mathrm{Hb}, 8.8 \mathrm{~g} / \mathrm{dL})$ and elevated levels of lactate dehydrogenase (454 IU/L) and soluble interleukin-2 receptor (sIL2-R, 6,030 U/mL). Commonly used autoantibodies and tumor markers for assessment of collagen diseases and cancers were all negative. CT scan revealed no lymphadenopathy, hepatosplenomegaly, or abnormal lung lesions. Gallium scintigraphy showed no abnormal accumulations. Brain magnetic resonance imaging (MRI) revealed a non-enhancing, high-intensity area of 17 $\mathrm{mm}$ in diameter in the pons on T2- and diffusion-weighted imaging (Figure 1A and B); however, no abnormal neurological signs were observed. Cerebrospinal fluid examination likewise found no abnormalities. Based on the high sIL2-R level, IVLBCL was suspected. A bone marrow biopsy showed a normocellular marrow with no apparent lymphoma cells. Genetic analysis of the bone marrow specimen showed no clonal rearrangement of T-cell receptor $C \beta 1$ or the immunoglobulin heavy chain $\mathrm{JH}$ region gene. We took healthyappearing skin randomly from the forearm, lower abdomen, and thigh for biopsy although no skin lesions were observed. All specimens revealed large B lymphoma cells within small veins and capillaries of the subcutaneous fat tissues but not outside the vessels (Figure 2A and B). Immunohistochemical studies showed that lymphoma cells were positive for CD20 (Figure 3), a B-cell marker, and negative for CD3, a T-cell
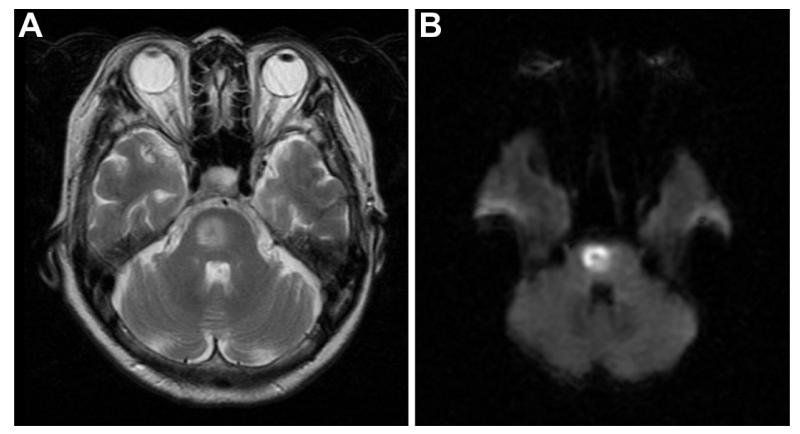

Figure I The image shows a $17 \mathrm{~mm}$ high intensity area in the pons on T2-weighted (A) and diffusion-weighted (B) magnetic resonance imaging (MRI) of the brain.
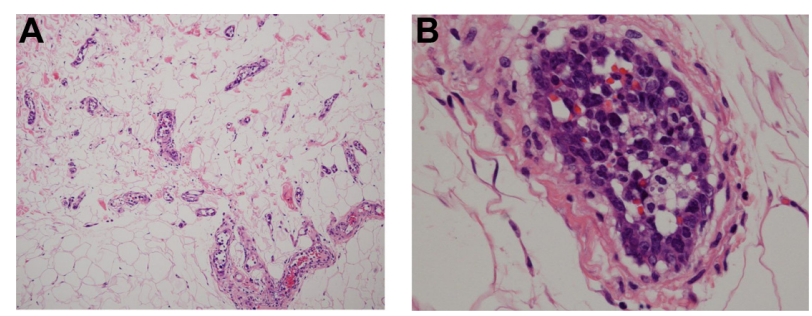

Figure 2 Pathological specimens.

Notes: (A) Skin biopsy specimen taken from the lower abdomen reveals proliferation of large lymphoma cells filling the vessels of hypodermic adipose tissue. (B) Numerous lymphoma cells with irregular nuclear contours and large nucleoli clustered are seen in small vessel lumens. Hematoxylin and eosin staining; magnification $(\mathbf{A}) \times 40($ B $) \times 100$.

marker. Based on these findings, a diagnosis of IVLBCL was made. The patient's poor general condition required a less toxic regimen, thus conventional R-CHOP therapy, consisting of rituximab $\left(375 \mathrm{mg} / \mathrm{m}^{2}\right)$, cyclophosphamide $(750 \mathrm{mg} /$ $\left.\mathrm{m}^{2}\right)$, doxorubicin $\left(50 \mathrm{mg} / \mathrm{m}^{2}\right)$, vincristine $\left(1.4 \mathrm{mg} / \mathrm{m}^{2}\right)$, and prednisolone $\left(60 \mathrm{mg} / \mathrm{m}^{2}\right)$, was started within 1 month of initial symptoms. After the first lumbar puncture for spinal fluid examination, the patient did not accept repeating it due to its invasiveness. For this reason, we treated the patient without any intrathecal treatment. After the first cycle of systemic chemotherapy, the patient had resolution of fever and peripheral edema, as well as improvement in $\mathrm{Hb}$, lactate dehydrogenase, and sIL2-R levels. After eight cycles of R-CHOP therapy, the pontine lesion had completely disappeared (Figure 4A and B). Therefore, the asymptomatic reversible pontine lesion was considered as IVLBCL involvement. During follow-up, the value of sIL2-R had been within reference range. Currently at 5 years after diagnosis, the patient has been doing well with

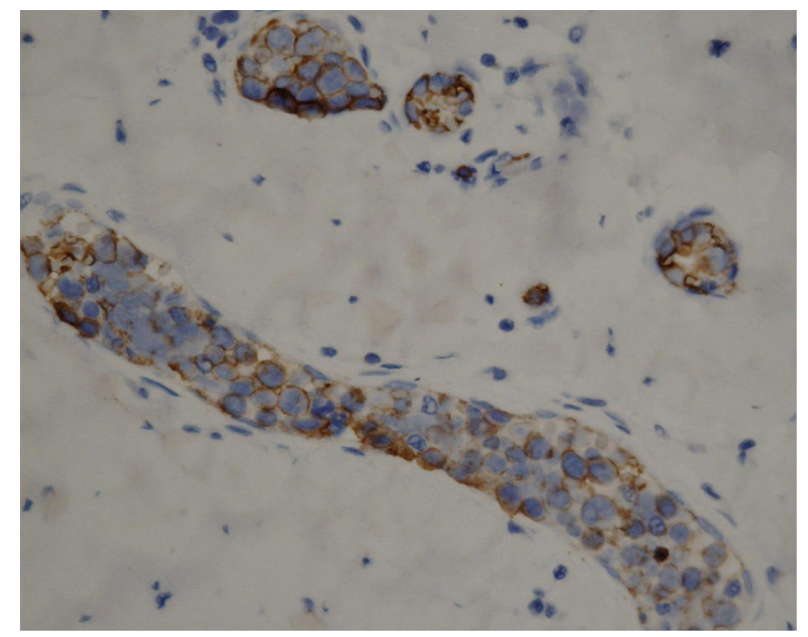

Figure 3 Immunohistochemistry demonstrating positivity of intravascular lymphoma cells for CD20.

Note: Magnification $\times 100$. 

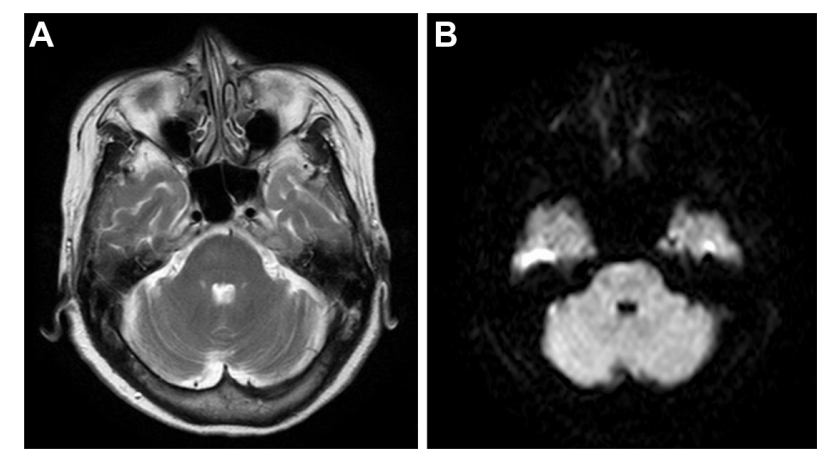

Figure 4 Magnetic resonance imaging (MRI) of the brain after receiving chemotherapy Notes: Pontine lesion on T2-weighted (A) and diffusion-weighted (B) MRI of the brain completely resolved after eight cycles of rituximab plus cyclophosphamide, doxorubicin, vincristine, and prednisone therapy.

no recurrence and returned to work without any neurological disorders.

\section{Discussion}

The present report describe a case of IVLBCL with CNS involvement that achieved complete remission for at least 5 years in response to R-CHOP therapy. Patients with IVLBCL with CNS involvement have a high risk of developing CNS recurrence and poor outcomes, even if they receive intensive chemotherapy like autologous stem cell transplantation. ${ }^{5}$ There is no reported case that had maintained complete remission for over 5 years.

Clinical manifestations of IVLBCL are known to differ between Asian and Western countries. ${ }^{4}$ In Western countries, IVLBCL often involves the skin and CNS. While IVLBCL in Asian countries tends to show only few skin lesions, ${ }^{6}$ random skin biopsy still appears useful to diagnose IVLBCL in Japan. ${ }^{3,7}$ In the present case, biopsied specimens were taken from apparently healthy skin. Even when biopsy is not easily available, in a case where IVLBCL is clinically suspected, for example, when the patient has an increased level of sIL2-R with or without lymphadenopathy, it is advisable to include random skin biopsies in the initial work-up to facilitate early diagnosis.

Rituximab-containing chemotherapies appear to improve clinical outcomes for IVLBCL patients. ${ }^{4}$ Additionally, a retrospective analysis demonstrated that rituximab might reduce the risk of CNS recurrence in IVLBCL patients. ${ }^{5}$ Those facts indicate that IVLBCL should be treated with regimens including rituximab. Although a few case reports showed that a patient with IVLBCL with pontine involvement was successfully treated with a rituximab containing regimen, ${ }^{8,9}$ the treatment effect of rituximab against IVLBCL with CNS involvement has not been clarified. ${ }^{4,5}$ Previous reports proposed that patients with IVLBCL with CNS involvement should be treated with regimens similar to those used for primary or secondary CNS lymphoma, ${ }^{10}$ including agents showing higher bioavailability in the CNS such as methotrexate or cytarabine. ${ }^{11,12}$ Besides, a case report suggested that intrathecal chemotherapy is a useful treatment for IVLBCL with CNS involvement. ${ }^{8}$ However, the results in this case suggest that R-CHOP can be effective for early IVLBCL with CNS lesions. In fact, the blood-brain barrier (BBB) is likely to block access of drugs to sites of infiltrative tumors; thus, the effectiveness of R-CHOP on CNS lymphomas is not promising. ${ }^{13}$ In that respect, as lymphoma cells must be present in vessels, drug efficacy for IVLBCL does not necessarily reflect vascular permeability; however, some IVLBCL cases indicate that minimal extravascular infiltration around the involved vessels occurs in the course of the disease. ${ }^{14}$ Therefore, early diagnosis and early initiation of R-CHOP may have contributed to the favorable response, despite CNS involvement, in the present case.

Regarding the drug metabolism, verapamil and all drugs contained in CHOP regimen are metabolized by liver enzyme cytochrome P 3A4 (CYP3A4). Due to this fact, it is worth considering that the metabolization of these drugs was affected by the drug-drug interaction, although it is difficult to analyze plasma drug concentrations retrospectively.

In the present case, the patient was using $80 \mathrm{mg} /$ day of verapamil and $0.25 \mathrm{mg} /$ day of digoxin for paroxysmal supraventricular tachycardia. Verapamil is a potent inhibitor of p-glycoprotein, which plays an important role in anticancer drug resistance in malignant lymphoma ${ }^{15}$ and limits the access of systemic drugs across the BBB. ${ }^{16}$ Digoxin is also a substrate of p-glycoprotein and might modulate BBB permeability to various drugs. ${ }^{17}$ In in vitro experiments in a previous report, inhibition of p-glycoprotein using $0.1 \mu \mathrm{M} / \mathrm{L}$ of verapamil resulted in reversal of p-glycoprotein-mediated doxorubicin and vincristine resistance in lymphoma cells. ${ }^{18}$ According to the manufacturer's data sheet of verapamil, the $\mathrm{C}_{\text {max }}$ (the maximum serum concentration of drug) of $80 \mathrm{mg}$ of verapamil sufficiently reaches $0.1 \mu \mathrm{M} / \mathrm{L}$. In fact, a combinational treatment effect between verapamil and anticancer agents for lymphoma patients has been reported previously. ${ }^{15}$ Therefore, taking verapamil during chemotherapy might contribute to complete remission despite CNS involvement in the present case.

In conclusion, treatment strategies for IVLBCL with CNS involvement are still controversial. The patient showed a favorable outcome after early diagnosis and the chemotherapy with verapamil. The present case suggests that early initiation of therapy and chemotherapy combined with p-glycoprotein inhibitors play an important role in treatment of IVLBCL 
with CNS involvement. Further retrospective investigation into the time of initiation of therapy and drug interaction between p-glycoprotein inhibitors and anticancer agents in IVLBCL patients is needed.

\section{Disclosure}

The authors report no conflicts of interest in this work.

\section{References}

1. Ponzoni M, Ferreri AJ, Campo E, et al. Definition, diagnosis, and management of intravascular large B-cell lymphoma: proposals and perspectives from an international consensus meeting. J Clin Oncol. 2007;25(21):3168-3173.

2. Shimada K, Kinoshita T, Naoe T, Nakamura S. Presentation and management of intravascular large B-cell lymphoma. Lancet Oncol. 2009;10(9): 895-902.

3. Asada N, Odawara J, Kimura S, et al. Use of random skin biopsy for diagnosis of intravascular large B-cell lymphoma. Mayo Clin Proc. 2007; 82(12):1525-1527.

4. Shimada K, Matsue K, Yamamoto K, et al. Retrospective analysis of intravascular large B-cell lymphoma treated with rituximab-containing chemotherapy as reported by the IVL study group in Japan. J Clin Oncol. 2008;26(19):3189-3195.

5. Shimada K, Murase T, Matsue K, et al. Central nervous system involvement in intravascular large B-cell lymphoma: a retrospective analysis of 109 patients. Cancer Sci. 2010;101(6):1480-1486.

6. Murase T, Yamaguchi M, Suzuki R, et al. Intravascular large B-cell lymphoma (IVLBCL): a clinicopathologic study of 96 cases with special reference to the immunophenotypic heterogeneity of CD5. Blood. 2007;109(2):478-485.

7. Matsue K, Asada N, Odawara J, et al. Random skin biopsy and bone marrow biopsy for diagnosis of intravascular large B cell lymphoma. Ann Hematol. 2011;90(4):417-421.
8. Sekiguchi Y, Shimada A, Imai H, et al. Intravascular large B-cell lymphoma with pontine involvement successfully treated with R-CHOP therapy and intrathecal administration: a case report and review of literature. Int J Clin Exp Pathol. 2014;7(6):3363-3369.

9. Nakazato T, Suzuki K, Mihara A, Sanada Y, Yoshida S, Kakimoto T. [Intravascular large B-cell lymphoma with pontine involvement successfully treated with R-hyper-CVAD/R-MTX-Ara-C regimen]. Rinsho Ketsueki. 2010;51(2):148-152. Japanese.

10. Zuckerman D, Seliem R, Hochberg E. Intravascular lymphoma: the oncologist's "great imitator". Oncologist. 2006;11(5):496-502.

11. Massimino M, Giardini R, Cefalo G, et al. Intravascular lymphomatosis (IL) in a child mimicking a posterior fossa tumor. J Neurooncol. 2001;51(1):47-50.

12. Moussouttas M. Intravascular lymphomatosis presenting as posterior leukoencephalopathy. Arch Neurol. 2002;59(4):640-641.

13. Wang CC, Carnevale J, Rubenstein JL. Progress in central nervous system lymphomas. Br J Haematol. 2014;166(3):311-325.

14. Imai $\mathrm{H}$, Kajimoto $\mathrm{K}$, Taniwaki $\mathrm{M}$, et al. Intravascular large B-cell lymphoma presenting with mass lesions in the central nervous system: a report of five cases. Pathol Int. 2004;54(4):231-236.

15. Miller TP, Grogan TM, Dalton WS, Spier CM, Scheper RJ, Salmon SE. P-glycoprotein expression in malignant lymphoma and reversal of clinical drug resistance with chemotherapy plus high-dose verapamil. J Clin Oncol. 1991;9(1):17-24.

16. Cordon-Cardo C, O’Brien JP, Casals D, et al. Multidrug-resistance gene (P-glycoprotein) is expressed by endothelial cells at blood-brain barrier sites. Proc Natl Acad Sci U SA. 1989;86(2):695-698.

17. Verschraagen M, Koks CH, Schellens JH, Beijnen JH. P-glycoprotein system as a determinant of drug interactions: the case of digoxinverapamil. Pharmacol Res. 1999;40(4):301-306.

18. Noguchi K, Kawahara H, Kaji A, Katayama K, Mitsuhashi J, Sugimoto Y. Substrate-dependent bidirectional modulation of P-glycoproteinmediated drug resistance by erlotinib. Cancer Sci. 2009;100(9): 1701-1707.
OncoTargets and Therapy

\section{Publish your work in this journal}

OncoTargets and Therapy is an international, peer-reviewed, open access journal focusing on the pathological basis of all cancers, potential targets for therapy and treatment protocols employed to improve the management of cancer patients. The journal also focuses on the impact of management programs and new therapeutic agents and protocols on

\section{Dovepress}

patient perspectives such as quality of life, adherence and satisfaction. The manuscript management system is completely online and includes a very quick and fair peer-review system, which is all easy to use. Visit http://www.dovepress.com/testimonials.php to read real quotes from published authors. 